\title{
Correspondence
}

\section{To convey or not to convey?}

The process of conveyance with the Deprivation of Liberty Safeguards (DoLS) is an important issue. ' Conveyance can involve restraint, which does not usually amount to a deprivation of liberty and is covered by the Mental Capacity Act 2005, Sections 5 and 6. Paragraphs 2.14 and 2.15 of the Deprivation of Liberty Safeguards Code of Practice ${ }^{2}$ attempt to deal with this issue, although it is worth examining recent case law for an answer.

In DCC v KH (2009) ${ }^{3}$ it was suggested that a standard authorisation would be sufficient to return an individual to the care home or hospital (from a place of residence), where the deprivation of liberty has been authorised, without any additional authority. ${ }^{4}$ This judgment suggests that permission from the court is not required when returning somebody to where there is a standard authorisation for them to be deprived of their liberty. The DoLS Code of Practice states: 'In almost all cases, it is likely that a person can be lawfully taken to a hospital or a care home under the wider provisions of the Act, as long as it is considered that being in the hospital or care home will be in their best interests' (par. 2.14).

Notably, paragraph 2.15 of the Code describes 'exceptional circumstances' when conveyance could amount to a deprivation of liberty and an order from the Court of Protection (to provide a residence order) would be necessary. With the majority of complaints regarding the Court of Protection originating from the length of the process and delays, ${ }^{5}$ effective planning for conveyance is advisable.

1 Shah A, Heginbotham C. Newly introduced deprivation of liberty safeguards: anomalies and concerns. Psychiatrist 2010; 34: 243-5.

2 DCC v KH (2009) COP 11729380.

3 Ministry of Justice. The Mental Capacity Act 2005: Deprivation of Liberty Safeguards. Code of Practice to Supplement the Main Mental Capacity Act 2005 Code of Practice. TSO (The Stationery Office), 2008.

4 Department of Health. Briefings on Legal Cases. Department of Health, 2010 (http://www.dh.gov.uk/en/Healthcare/Mentalhealth/ DH_111770).

5 Judiciary of England and Wales. Court of Protection: 2009 Report. Judiciary of England and Wales, 2010.

Jaspreet S. Phull ST6 in forensic psychiatry, and DoLS assessor, Nottinghamshire NHS Trust, Leicester, email: jas.phull@nottshc.nhs.uk doi: $10.1192 / \mathrm{pb} .35 .1 .30$

\section{Smoking and people with mental illness}

People with mental health problems smoke significantly more, have increased levels of nicotine dependency and are therefore at even greater risk of smoking-related harm than the general population. $^{1,2}$

We surveyed the smoking habits of in-patients on four adult open wards in Durham and compared them with those of the general UK population. The national statistics were obtained from Action on Smoking and Health Fact Sheets ${ }^{3}$ and from the Office for National Statistics. ${ }^{4}$

The overall smoking prevalence for the in-patients was three times the national average (65\% v. $21 \%)$. Addiction to nicotine can be measured by noting how long after waking a person smokes their first cigarette: $35 \%$ of in-patients and $16 \%$ of the general population had their cigarette in the first 5 minutes. Furthermore, $57 \%$ of the general population and $70 \%$ of in-patients said they would find it hard to go for a whole day without smoking. Worryingly, $78 \%$ of the in-patients said that they smoked more when they are admitted; the reasons given included boredom and a belief that smoking reduces sideeffects of medication and causes weight loss. More than half of the patients (60\%) expressed a desire to cut down smoking. It can be concluded that in-patients smoke more and are more addicted than the general population.

Following this survey, we have recommended that the in-patients should be offered advice on smoking cessation at the time of the admission and discharge. Treatment should also be offered routinely, particularly as a review of smoking cessation treatments for people with mental illness concluded that pharmacological aids that are given to the general population can be equally effective in helping people with mental illness to stop smoking. ${ }^{5}$ However, care must be taken to avoid adverse medication interactions and to monitor antipsychotic medication in particular as cigarette consumption declines.

Boredom as an excuse for smoking should be challenged with structured occupational therapy programme. We also feel that patients should be encouraged to manage their weight by exercising and could be helped with advice from a dietician.

We would like to know if other readers have had similar experiences regarding smoking on in-patient wards, especially as there are plans to percolate the smoking ban down to lower levels of security. We are aware that some of the healthcare wings in prison are also now smoke free.

1 Cormac I, Creasey S, McNeill A, Ferriter M, Huckstep B, D'Silva K. Impact of a total smoking ban in a high secure hospital. Psychiatrist 2010; 34: 413-7.

2 Faculty of Public Health. Mental Health and Smoking: A Position Statement. Faculty of Public Health, 2008.

3 Action on Smoking and Health Fact Sheets. Smoking Statistics: Who Smokes and How Much. ASH, 2010 (www.ash.org.uk/files/documents/ ASH_106.pdf).

4 Robinson S, Bugler C. General Lifestyle Survey 2008: Smoking and Drinking among Adults, 2008. Office for National Statistics, 2010.

5 Campion J, Checinski K, Nurse J. Review of smoking cessation treatments for people with mental illness. Adv Psychiatr Treat 2008; 14: 208-16.

Pratish B. Thakkar is consultant forensic psychiatrist, Tees, Esk and Wear Valleys NHS Foundation Trust, Middlesbrough, email: pratish.thakkar@tewv.nhs.uk, Jose Garcia is consultant psychiatrist, Tees, Esk and Wear Valleys NHS Foundation Trust, Durham, and Leslie Burton is consultant psychiatrist, Cambian Healthcare, Darlington.

doi: 10.1192/pb.35.1.30a

\section{More can be done to improve readability of patient letters}

The quality of communication with our patients is of paramount importance and it is crucial to promoting successful therapeutic engagement. 